\title{
Влияние температуры на морфологию планарных нанопроволок GaAs (моделирование)
}

\author{
(C) А.А. Спирина ${ }^{1}$, Н.Л. Шварц ${ }^{1,2}$ \\ ${ }^{1}$ Институт фризики полупроводников им. А.В. Ржанова Сибирского отделения Российской академии наук, \\ 630090 Новосибирск, Россия \\ ${ }^{2}$ Новосибирский государственный технический университет, \\ 630087 Новосибирск, Россия \\ E-mail: spirina.anna.alex@gmail.com
}

Поступила в Редакцию 26 сентября 2019 г.

В окончательной редакции 30 сентября 2019 г.

Принята к публикации 30 сентября 2019 г.

С помощью кинетической решеточной модели Монте-Карло проанализирован самокаталитический рост планарных GaAs нанопроволок. Рост нанопроволок по механизму пар-жидкость-кристалл рассматривался для подложек GaAs с ориентациями (111)A и (111)В. Исследовалось влияние температуры и расположения капель галлия на морфологию и направление роста планарных $\mathrm{GaAs}$ нанопроволок. Выявлен диапазон температур, в котором наблюдался стабильный рост планарных GaAs-нанопроволок на поверхности $\mathrm{GaAs}(111) \mathrm{A}$. Выбранное асимметричное расположение капель позволяет получать однонаправленный рост нанопроволок.

Ключевые слова: $\mathrm{GaAs}$, планарные нанопроволоки, моделирование, Монте-Карло.

DOI: 10.21883/FTP.2020.02.48911.9270

\section{1. Введение}

В последнее десятилетие наряду с интенсивным изучением вертикальных $\mathrm{A}^{\mathrm{III}} \mathrm{B}^{\mathrm{V}}$ нитевидных нанокристаллов [1] большой интерес вызывают планарные нанопроволоки [2] благодаря их совместимости со стандартной планарной технологией [3]. На сегодняшний день уже созданы полевые транзисторы и аксиальные $p-n$-переходы на базе планарных GaAs-нанопроволок с образцовыми электрофизическими характеристиками [4].

Ранее при определенных условиях роста вертикальных нанокристаллов наблюдали формирование планарных нанопроволок и считали их дефектами выбранного режима роста [5]. В связи с перспективой использования планарных $\mathrm{A}^{\mathrm{III}} \mathrm{B}^{\mathrm{V}}$ нанокристаллов в настоящее время ведется целенаправленный поиск условий их формирования. Одним из способов формирования планарных нанопроволок является рост кристаллов с помощью капель-катализаторов по механизму паржидкость-кристалл методом молекулярно-лучевой эпитаксии. Такие планарные наноструктуры эпитаксиально связаны с подложкой, имеют совершенную структуру и, в отличие от вертикальных, не имеют дефекта двойникования плоскостей [2]. В качестве катализатора роста нанопроволок по механизму пар-жидкостькристалл (ПЖК) в основном используют золото [1,2], что является проблемой для создания оптоэлектронных приборов на основе нанопроволок. Атомы золота в процессе роста встраиваются в растущий кристалл, образуя центры безызлучательной рекомбинации, ухудшая характеристики приборов [6]. Решение этой проблемы было найдено для вертикальных нитевидных нанокристаллов и заключалось в использовании катализатора- металла, входящего в состав растущей проволоки, т.е. в самокаталитическом росте нанопроволок [5,7]. Однако работ по самокаталитическому росту планарных $\mathrm{A}^{\mathrm{III}} \mathrm{B}^{\mathrm{V}}$ нанопроволок по механизму ПЖК в открытой печати нет, что связано с узким диапазоном ростовых условий таких структур и высокими требованиями к свойствам поверхности подложек. Работы по имитационному моделированию роста нанопроволок посвящены лишь вертикальным наноструктурам и рассматривают только отдельные аспекты их формирования [8-10]. Ранее получены результаты по росту вертикальных нитевидных нанокристаллов $\mathrm{Si}, \mathrm{GaAs}$ и InAs с помощью моделирования методом Монте-Карло [11-13].

Изготовление ряда приборов на основе планарных нанопроволок предполагает наличие однонаправленного массива таких кристаллов. Рост нанокристаллов $\mathrm{A}^{\mathrm{III}} \mathrm{B}^{\mathrm{V}}$ в выделенном направлении определяется потоком частиц V группы, поступающего в каплю, т.е. кристалл растет в том направлении откуда поступление материала V группы максимально. Соответствующего распределения частиц V группы вблизи капли- катализатора можно достичь с помощью специального расположения капель на поверхности, заданных свойств поверхностного слоя (скорость диффузии и скорость десорбции частиц $\mathrm{V}$ группы с поверхности) и оптимальных ростовых условий (скорость осаждения частиц III и V групп, температура).

Данная работа направлена на поиск оптимальных условий роста однонаправленного массива планарных нанопроволок GaAs. Рассматривалось влияние температуры на морфологию GaAs-кристаллов с помощью моделирования методом Монте-Карло. В качестве катализатора роста GaAs-нанопроволок по механизму пар- 


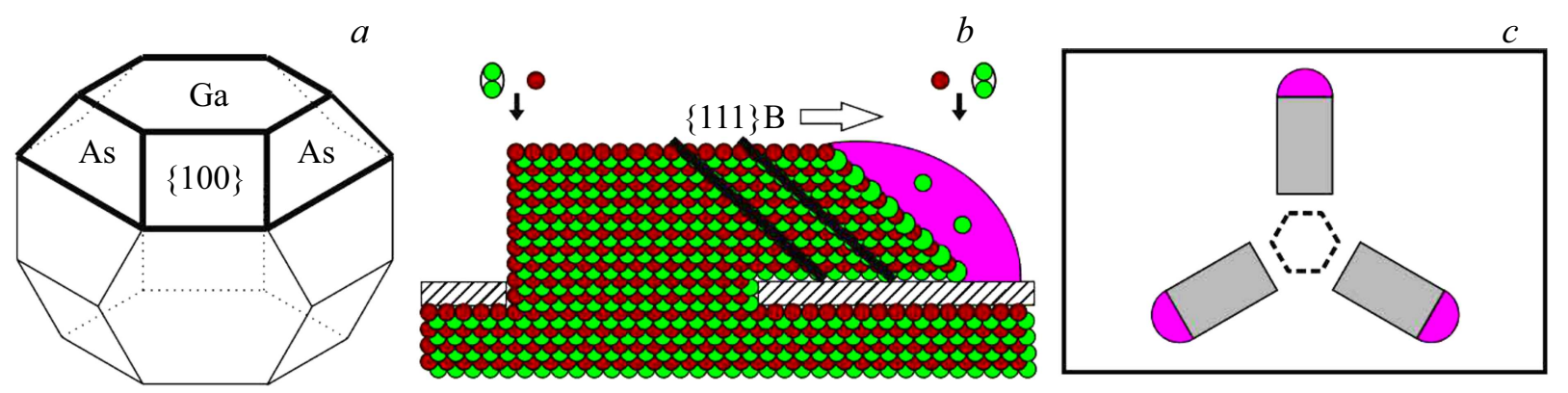

Рис. 1. Схематичные изображения $(a)$ равновесной формы GaAs, формирующегося под каплей Ga; планарной GaAsнанопроволоки: вид сбоку $(b)$, вид сверху $(c)$. $\mathrm{Ga}(s)$ показан коричневым, $\mathrm{Ga}(l)$ - розовым, Аs — зеленым, пленка-маска белым, Аs 2 обведен эллипсом. (Цветная версия рисунка - в электронной версии статьи).

жидкость-кристалл использовался жидкий галлий. Специальное расположение капель галлия на подложках GaAs с ориентациями (111)A и (111)В обеспечивало формирование планарных нанопроволок GaAs в заданном направлении.

\section{2. Результаты моделирования}

Моделирование самокаталитического роста планарных GaAs-нанопроволок проводилось с помощью программного комплекса SilSim3D, основанного на трехмерной кинетической решеточной модели Монте-Карло [14]. Рассматривалась четырехкомпонентная система, состоящая из мышьяка в атомарном и молекулярном виде $\left(\mathrm{As}, \mathrm{As}_{2}\right)$, галлия в твердом и жидком состоянии $(\mathrm{Ga}(s), \mathrm{Ga}(l))$. В модели учтены следующие элементарные события: адсорбция $\mathrm{Ga}(s)$ и $\mathrm{As}_{2}$, диффузия компонентов по поверхности, десорбция $\mathrm{Ga}$ и $\mathrm{As}_{2}$, распад и образование $\mathrm{As}_{2}$ посредством обратимой реакции $\mathrm{As}+\mathrm{As} \leftrightarrow \mathrm{As}_{2}$, диффузия As в жидком галлии, растворение и кристаллизация GaAs. Растворение GaAs имитировалось через взаимодействия твердого галлия и мышьяка с жидким галлием $\mathrm{Ga}(s)+\mathrm{Ga}(l) \rightarrow \mathrm{Ga}(l)+\mathrm{Ga}(l)$ и $\mathrm{As}+\mathrm{Ga}(l) \rightarrow \mathrm{Ga}(l)+$ As. Кристаллизация GaAs peализовывалась при взаимодействии жидкого галлия с мышьяком $\mathrm{Ga}(l)+\mathrm{As} \rightarrow \mathrm{Ga}(s)+\mathrm{As}$. Каждому событию соответствуют определенные энергии активации, выбор которых проводился на основе согласования экспериментальных и модельных температурных зависимостей растворения GaAs в жидком галлии и температурных зависимостей равновесного давления паров GaAs $[15,16]$.

Схема роста планарных $\mathrm{A}^{\mathrm{III}} \mathrm{B}^{\mathrm{V}}$ нанопроволок показана на рис. 1. Поверхность подложки покрыта пленкой-маской со сквозными отверстиями, в которые помещались капли галлия. В процессе осаждения галлия и мышьяка на поверхности подложки под каплей формируется трехмерный GaAs-нанокристалл, который схематично изображен на рис. 1, $a$. Форма кристалла обусловлена кристаллографией и при ростовых условиях, обеспечивающих планарный рост, напоминает половину усеченного октаэдра. Боковая поверхность такого кристалла состоит из трех плоскостей $\{111\}$, соединенных плоскостями $\{100\}$. Ориентация верхней плоскости 3D кристалла относится к семейству $\{111\}$ и задается поверхностью подложки. После формирования трехмерного кристалла под каплей начинается рост планарных нанопроволок, т.е. перемещение капли-затравки путем приращения кристалла нитевидной формы (рис. 1,b). Капля-катализатор перемещается в направлении поверхностей $\{111\} \mathrm{B}$, являющихся фронтом роста нитевидных $\mathrm{A}^{\mathrm{III}} \mathrm{B}^{\mathrm{V}}$ нанопроволок [2]. Таким образом планарный рост нанопроволок на основе полупроводников $\mathrm{A}^{\mathrm{III}} \mathrm{B}^{\mathrm{V}}$ возможен в трех направлениях, как показано на рис. 1, $c$.

Температура роста является одним из главных параметров ростового процесса. При фиксированном отношении потоков $F\left(\mathrm{As}_{2}\right)$ и $F(\mathrm{Ga})$ температура роста менялась от 800 до $950 \mathrm{~K}$. На рис. 2 представлены результаты моделирования роста планарных GaAs-проволок на подложках $\mathrm{GaAs}(111) \mathrm{B}$ при $F\left(\mathrm{As}_{2}\right) / F(\mathrm{Ga})=5$. Угол между фронтом роста планарных нанопроволок и поверхностью (111)В составляет $71.2^{\circ}$ (рис. 2,a). При низких температурах $T \sim 800 \mathrm{~K}$ капля галлия сразу разделяется на четыре части, как показано на рис. $2, b$. Три капли инициируют формирование горизонтальных проволок, одна - вертикальную. Разделение капли связано с тем, что при такой температуре мышьяк слабо испаряется с поверхности. Это приводит к большому диффузионному сбору мышьяка с поверхности подложки в каплю и, как следствие, формированию под каплей всех возможных (четырех) фасеток $\{111\}$ В на границе раздела капля-кристалл. В дальнейшем размер капель галлия в процессе роста нанопроволок быстро уменьшается в результате высокой концентрации мышьяка в капле и ускоренной кристаллизации капли на границе раздела капля-кристалл. После поглощения капли происходит радиальный рост планарных нанопроволок за счет встраивания атомов в боковые стенки кристалла, что приводит к образованию сплошной GaAs-пленки на поверхности подложки. Этот результат находится в соответствии с экспериментом [5], где было показано, что при $T \sim 800 \mathrm{~K}$ на поверхности пленки-маски вместо нанопроволок формируется сплошной слой GaAs. 


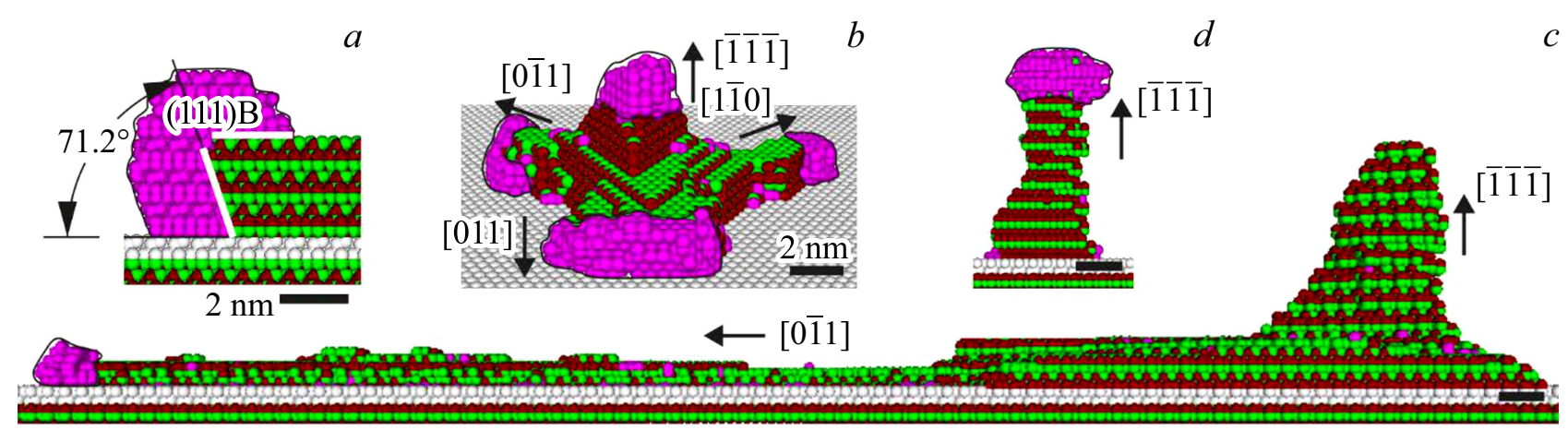

Рис. 2. Модельные поверхности $\mathrm{GaAs}(111)$ В после роста при разных температурах, $\mathrm{K}: 850(a, c), 800(b), 950(d) ; F(\mathrm{Ga})=3 \mathrm{MC} / \mathrm{c}$, $F\left(\mathrm{As}_{2}\right)=15 \mathrm{MC} / \mathrm{c}$.

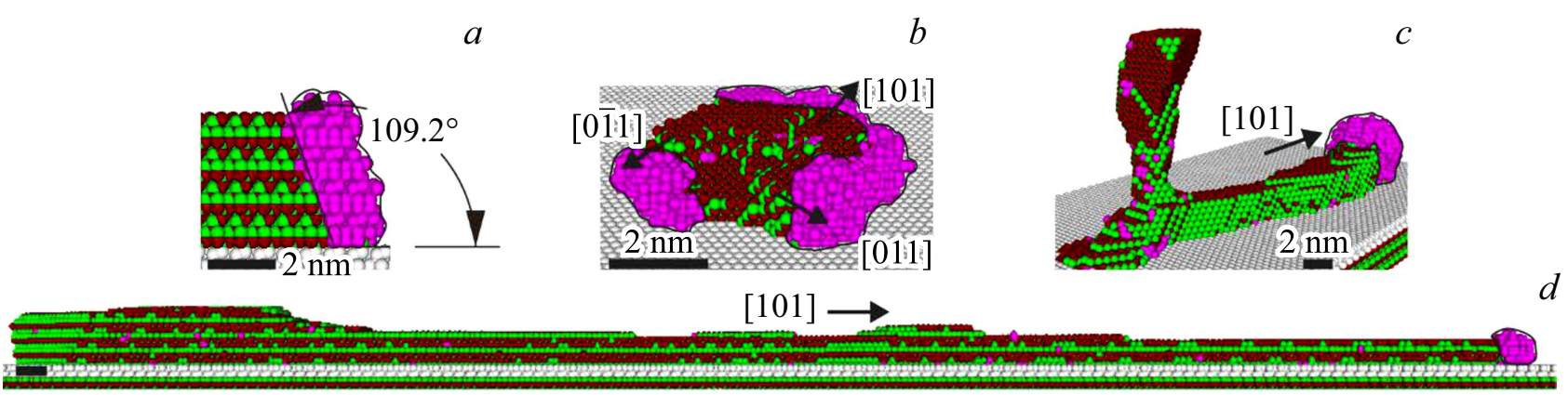

Рис. 3. Модельные поверхности $\mathrm{GaAs}(111) \mathrm{A}$ после роста при разных температурах, $\mathrm{K}: 890(a, d), 800(b), 950(c) ; F(\mathrm{Ga})=3 \mathrm{MC} / \mathrm{c}$, $F\left(\mathrm{As}_{2}\right)=15 \mathrm{MC} / \mathrm{c}$.

Увеличение температуры с 800 до $950 \mathrm{~K}$ приводит к формированию протяженных планарных GaAs-нанопроволок, которые в процессе роста срываются на вертикальный режим роста. Изменение направления роста связано с наличием конкурирующей горизонтальной фасетки (111)В на границе раздела капля-кристалл (рис. 2, $a$ ), формирование которой задается ориентацией подложки. При увеличении температуры возрастает скорость испарения мышьяка и уменьшается диффузионный сбор мышьяка с поверхности пленки в каплю, в результате чего на границе раздела капля-кристалл образуется меньше фасеток $\{111\} \mathrm{B}$, инициирующих рост планарных нанопроволок. На рис. 2, $c$ показан вид модельной подложки после осаждения галлия и мышьяка при $T=850 \mathrm{~K}$. На начальной стадии роста формировалась планарная GaAs-нанопроволока. В процессе приращения кристалла происходило смещение границы раздела капля-кристалл, т.е. капля смачивала не только фронт роста планарной нанопроволоки, но и верхнюю огранку GaAs-кристалла, как показано на рис. 2, a. Это привело к расщеплению капли галлия на две части и одновременному росту двух нанопроволок GaAs: планарной и вертикальной. Капля галлия, расположенная на вершине вертикального кристалла, поглотилась ввиду меньшего диффузионного сбора галлия с подложки по сравнению с каплей, инициирующей рост планарной нанопроволоки.
При высоких температурах $T \sim 950 \mathrm{~K}$ наблюдался только вертикальный рост GaAs-проволок (рис. 2,d). Вертикальный рост нанопроволок связан с малым диффузионным сбором мышьяка с подложки. При данной температуре мышьяк интенсивно испаряется с поверхности подложки и поступает в каплю непосредственно из потока, в результате чего растут только вертикальные нанопроволоки GaAs. Капли при вертикальном режиме роста проволок быстро поглощаются из-за малого диффузионного галлия с подложки, связанного с большой скоростью испарения галлия при $T=950 \mathrm{~K}$. Максимально длинные планарные GaAs-проволоки на подложках $\mathrm{GaAs}(111)$ В получены в области температур $850-890 \mathrm{~K}$.

На поверхности $\mathrm{GaAs}(111) \mathrm{A}$ рост планарных кристаллов более устойчив. Угол между фронтом роста планарных нанопроволок и поверхностью (111)A составляет $109.2^{\circ}$ (рис. 3, $a$ ). При низких температурах роста $(T=800 \mathrm{~K})$ под каплей галлия формируются все возможные фасетки $\{111\}$ В. На рис. $3, b$ показан вид модельной подложки после роста при $800 \mathrm{~K}$, где капля галлия разделилась на три части, инициируя рост трех планарных проволок. Как и на поверхности (111)В, дальнейшее осаждение галлия и мышьяка на поверхность приводит к поглощению капель галлия и формированию сплошной пленки GaAs. 
$a$ $b$

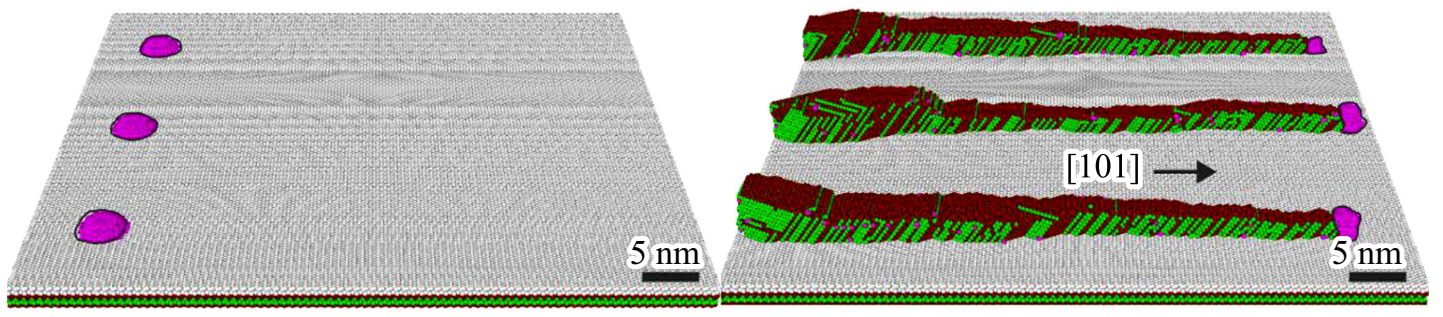

Рис. 4. Фрагмент модельной подложки $\mathrm{GaAs}(111) \mathrm{A}$ с тремя каплями $\mathrm{Ga}$ до $(a)$ и после $(b)$ роста при $T=890 \mathrm{~K} ; F(\mathrm{Ga})=3 \mathrm{MC} / \mathrm{c}$, $F\left(\mathrm{As}_{2}\right)=15 \mathrm{MC} / \mathrm{c}$.

При увеличении температуры роста до $T \sim 950 \mathrm{~K}$ уже на начальном этапе рост кристаллов на поверхности $\mathrm{GaAs}(111) \mathrm{A}$ происходит под углом к поверхности 54․ Непланарный рост связан с увеличением скорости испарения мышьяка при повышении температуры. После формирования наклонной проволоки у ее основания может сформироваться новая капля галлия, которая становится катализатором роста планарной проволоки. Такой случай изображен на рис. $3, c$.

Оптимальной температурой для стабильного роста планарных GaAs-нанопроволок при выбранных значениях потоков является температура $T=890 \mathrm{~K}$. Показанная на рис. $3, d$ нанопроволока непрерывно связана с пассивирующим слоем, объемные дефекты на протяжении всей длины кристалла не обнаружены. При данной температуре и соотношении потоков $\mathrm{As} / \mathrm{Ga}$ на поверхности присутствует достаточное количество мышьяка, чтобы сформировать связанные с подложкой фасетки $\{111\}$ В и не поглотить каплю-катализатор. Нерешенной проблемой остается уменьшение толщины проволоки в процессе роста из-за уменьшения капли галлия.

Регулируя температуру или скорость осаждаемого вещества можно добиться формирования бездефектных планарных нанопроволок. Однако направление их роста остается неуправляемым без заранее заданного расположения капель-катализаторов. Специальное расположение капель галлия в модели задавалось следующим образом. В пассивирующем слое создавались отверстия, в которые помещались капли галлия. Такая подложка благодаря циклическим граничным условиям в латеральных направлениях имитирует случай бесконечного числа близкорасположенных капель галлия. На рис. 4, a приведен фрагмент модельной подложки с диаметром сквозных отверстий в пленке 5 нм до начала ростового процесса. Этот фрагмент содержит три капли $\mathrm{Ga}$, расположенных в один ряд. Расстояние между каплями в ряду составляет 15 нм, между рядами - 120 нм. Выбранная геометрия подложки приводит к выделенному направлению роста нанопроволок вдоль поверхности. Рост планарных кристаллов только в одном направлении обусловлен ограничением диффузионного сбора мышьяка с тех участков, которые попадают в радиус диффузионного сбора соседних капель, т. е. кристалл преимущественно растет в том направлении откуда поступление мышьяка максимально. На рис. 4, $b$ показан фрагмент модельной подложки $\mathrm{GaAs}(111) \mathrm{A}$ с тремя параллельными планарными GaAs-нанопроволоками.

\section{3. Заключение}

Проанализирован самокаталитический рост планарных GaAs-нанопроволок по механизму пар-жидкостькристалл с помощью Монте-Карло моделирования. Исследовались условия формирования однонаправленных массивов планарных нанопроволок на подложках $\mathrm{GaAs}$ с ориентациями (111)А и (111)В. Показано, что угол между фронтом роста планарных нанопроволок и поверхностью (111)А составляет $109.2^{\circ}$, а на поверхности (111)В - 71.2 . Рассматривалось влияние температуры и расположения капель-катализаторов на морфологию и направление роста планарных GaAs-нанопроволок. Выявлен диапазон температур, в котором наблюдалось формирование планарных нанопроволок. Выбрано специальное расположение капель галлия, при котором формировались однонаправленные планарные GaAs-нанопроволоки. На подложках $\mathrm{GaAs}(111) \mathrm{A}$ наблюдался более стабильный рост планарных GaAs-кристаллов, чем на $\operatorname{GaAs}(111) \mathrm{B}$.

\section{Финансирование работы}

Работа поддержана РФФИ (проект № 19-31-90023).

\section{Конфликт интересов}

Авторы заявляют, что у них нет конфликта интересов.

\section{Список литературы}

[1] P. Krogstrup, H.I. Jørgensen, E. Johnson, M.H. Madsen, C.B. Sørensen, A.F. i Morral, M. Aagesen, J. Nygard, F. Glas. J. Phys. D: Appl. Phys., 46 (31), 313001 (2013).

[2] S.A. Fortuna, J. Wen, I.S. Chun, X. Li. Nano Lett., 8 (12), 4421 (2008).

[3] Y. Chen, P. Kivisaari, M.-E. Pistol, N. Anttu. Nanotechnology, 29 (4), 045401 (2018). 
[4] W. Choi, E. Seabron, P.K. Mohseni, J.D. Kim, T. Gokus, A. Cernescu, P. Pochet, H.T. Johnson, W.L. Wilson, X. Li. ACS Nano, 11 (2), 1530 (2017).

[5] F. Bastiman, H. Küpers, C. Somaschini, L. Geelhaar. Nanotechnology, 27 (9), 095601 (2016).

[6] S. Breuer, C. Pfuller, T. Flissikowski, O. Brandt, H.T. Grahn, L. Geelhaar, H. Riechert. Nano Lett., 11 (3), 1276 (2011).

[7] S. Ambrosini, M. Fanetti, V. Grillo, A. Franciosi, S. Rubini. AIP Advances, 1, 042142 (2011).

[8] K. Sano, T. Akiyama, K. Nakamura, T. Ito. J. Cryst. Growth, 301-302, 862 (2007).

[9] Z. Dong, P. Kashkarov, H. Zhang. Nanoscale, 2, 524 (2010).

[10] K.K. Sabelfeld, V.M. Kaganer, F. Limbach, P. Dogan, O. Brandt, L. Geelhaar, H. Riechert. Appl. Phys. Lett., 103, 133105 (2013).

[11] A.G. Nastovjak, I.G. Neizvestny, N.L. Shwartz. Pure Appl. Chem., 84 (12), 2619 (2012).

[12] М.В. Князева, А.Г. Настовьяк, И.Г. Неизвестный, Н.Л. Шварц. ФТП, 49 (1), 63 (2015).

[13] A.G. Suprunets, M.A. Vasilenko, N.L. Shwartz. J. Phys.: Conf. Ser., 690, 012011 (2016).

[14] А.Н. Карпов, А.В. Зверев, А.Г. Настовьяк, С.В. Усенков, Н.Л. Шварц. Вычисл. методы и программирование, 15 (3), 388 (2014).

[15] A.A. Spirina, I.G. Neizvestny, N.L. Shwartz. Def. Diff. Forum, 386, 21 (2018)

[16] A.A. Spirina, N.L. Shwartz. Mater. Sci. Semicond. Process., 100, 319 (2019).

Редактор А.Н. Смирнов

\section{Influence of temperature on the planar GaAs nanowire morphology (simulation)}

A.A. Spirina ${ }^{1}$, N.L. Shwartz ${ }^{1,2}$

${ }^{1}$ Rzhanov Institute of Semiconductor Physics of Siberian Branch, Russian Academy of Sciences, 630090 Novosibirsk, Russia

${ }^{2}$ Novosibirsk State Technical University, 630087 Novosibirsk, Russia

Abstract Using a kinetic lattice Monte Carlo model, the selfcatalyzed growth of planar GaAs nanowires was analyzed. The nanowire growth via the vapor-liquid-crystal mechanism was considered. The effect of temperature and the catalyst droplet location on the morphology and growth direction of planar GaAs nanowires was studied. For $\mathrm{GaAs}(111) \mathrm{A}$ and $\mathrm{GaAs}(111) \mathrm{B}$ substrates, a temperature range corresponding to stable growth of planar GaAs nanowires was revealed. The special asymmetric arrangement of droplets allows the one-directional nanowire growth. 